\title{
Composition and color stability of anthocyanin-based extract from purple sweet potato
}

\author{
Xiu-li HE ${ }^{1}$, Xue-li LI ${ }^{1}$, Yuan-ping $\mathrm{LV}^{2 *}$, Qiang $\mathrm{HE}^{1 *}$
}

\begin{abstract}
Purple sweet potato (PSP) can provide products with attractive color besides nutritious benefits in food processing. So, the compositions and color stability of an aqueous anthocyanin-based PSP extract were investigated in order to promote its wide use in food industry. PSP anthocyanins were extracted with water, and nine individual anthocyanins $\left(48.72 \mathrm{ug} \mathrm{mL}^{-1}\right.$ in total, $24.36 \mathrm{mg} / 100 \mathrm{~g}$ fresh PSP in yield) were found by HPLC analysis. The PSP extract also contained $17.11 \mathrm{mg} \mathrm{mL}^{-1}$ of protein, $0.44 \mathrm{mg} \mathrm{mL}^{-1}$ of dietary fiber, $2.82 \mathrm{mg} \mathrm{mL}^{-1}$ of reducing sugars, $4.02 \mathrm{ug} \mathrm{mL}^{-1}$ of Se, $54.21 \mathrm{ug} \mathrm{mL}^{-1}$ of Ca and $60.83 \mathrm{ug} \mathrm{mL}$ of Mg. Changes in color and stability of the PSP extract, as affected by $\mathrm{pH}$, heat, light and extraction process, were further evaluated. Results indicated that PSP anthocyanins had good stability at $\mathrm{pH}$ 2.0-6.0, while the color of PSP extract kept stable during 30 days of storage at $20^{\circ} \mathrm{C}$ in dark. Both UV and fluorescent exposure weakened the color stability of PSP extract and UV showed a more drastic effect in comparison. A steaming pretreatment of fresh PSP is beneficial to the color stability.
\end{abstract}

Keywords: purple sweet potato; anthocyanins; color; stability.

Practical Application: Anthocyanin-based PSP extract is potential to be used as a natural colorant in food industry.

\section{Introduction}

In recent years, public concern about the safety of synthetic pigments led to increasing interest in the development of food colorants from plant tissues, especially from some edible sources. As a group of natural, water-soluble and nontoxic pigments, anthocyanins are widely distributed in plant world and display a variety of colors from orange to purple (Fossen et al., 1998; Janna et al., 2007; Lu et al., 2010). So, some anthocyanin-rich extracts from fruits and vegetables can be used as food colorants to replace the synthetic ones in consideration of consumer preference. In addition, anthocyanins also showed a number of biological functions, including antioxidant and anti-carcinogen activities, hepato-protection capacity and the ability to enhance memory (Cho et al., 2003; Hwang et al., 2011). Therefore, extending the use of anthocyanin-rich extracts is significant in food industry because they can provide products with potential health benefits besides attractive colors. Nevertheless, many anthocyanins are susceptible to heat, light, $\mathrm{pH}$, oxygen and some enzymes like polyphenol oxidase, which restricts their commercial application to food processing (Cavalcanti et al., 2011; Malien-Aubert et al., 2001). This susceptibility may vary with molecular structures, and some acylated anthocyanins were proved to be more stable than others (Montilla et al., 2010).

As a main crop grown worldwide with high yield, purple sweet potato (PSP) is rich in carbohydrate and dietary fiber. PSP showed stronger antioxidant activity than many other vegetables because it contains high content of anthocyanins (Zhang et al., 2009). In addition, owing to the fact that PSP anthocyanins (PSPAs) mainly exist in mono- or di-acylated forms (Montilla et al., 2010), they displayed better stability as compared to the pigments of strawberries, red cabbage, perilla and other plants (Zhang et al., 2009). As for food processing, this stability may allow the colored products a consistent quality during shelf life. Thus, PSP is a good source for the preparation of anthocyanin-based food colorant. Acidified methanol and ethanol are commonly used to extract anthocyanins from plant tissues (Castañeda-Ovando et al., 2009) and some new technologies such as microwave- and ultrasonic-assisted methods were also developed to promote the efficiency (Lien et al., 2012; Lu et al., 2010). However, in consideration of cost and environment, a water-extraction process is attractive in food industry. Such PSP extracts may serve as food coloring agents, and additionally it can be used as a main source for developing many products like beverage. Hence, PSPAs were extracted with water in this research and the main compositions of the extract, including protein, dietary fiber, metal ions and anthocyanins, were analyzed. The color stability of the anthocyanin-based extract, with respect to $\mathrm{pH}$, heat, light and extraction process, was further investigated. The results may promote anthocyanin-based PSP extract to be used as natural colorants in food industry.

\section{Materials and methods}

\subsection{Materials}

Purple sweet potatoes (PSP, variety G135, harvested in Oct, 2013) were provided by a local company (Chengdu city, Sichuan Province, China). Acetonitrile and acetic acid were HPLC grade and other chemicals were of analytical grade. 


\subsection{Preparation of PSP extract}

Fresh PSP tuber (50 g) was cut into pieces and mashed with $500 \mathrm{~mL}$ distilled water (without $\mathrm{pH}$ adjustment), followed by stirring at $37^{\circ} \mathrm{C}$ for $1 \mathrm{~h}$. The homogenate was then filtered and the filtrate was concentrated to $250 \mathrm{~mL}$ in a rotary evaporator $\left(55^{\circ} \mathrm{C}\right)$. The anthocyanin-based PSP extract was stored at $4{ }^{\circ} \mathrm{C}$ in dark. In order to investigate the effect of preheating on the color stability of PSP extract, fresh PSP pieces were steamed for $30 \mathrm{~min}$ or baked at $60^{\circ} \mathrm{C}$ for $30 \mathrm{~min}$ before mashing treatment. $\mathrm{HCl}$ and $\mathrm{NaOH}(0.1 \mathrm{M})$ were employed to adjust the $\mathrm{pH}$ of PSP extract when necessary.

\subsection{Composition analysis of PSP extract}

To conduct metal ions analysis, $5 \mathrm{~mL}$ PSP extract was completely digested into $10 \mathrm{~mL}$ nitric acid, which was then diluted to $50 \mathrm{~mL}$ with distilled water. The contents of metal ions including $\mathrm{Se}, \mathrm{Ca}$ and $\mathrm{Mg}$ in the PSP extract were determined by using inductively coupled plasma atomic emission spectrometry (ICP-AES, Perkin-Elmer Optima 2100DV, Germany). Protein was measured by Bradford method using bovine serum albumin as reference (Kamizake et al., 2003). The contents of reducing sugars and dietary fiber were determined according to 3, 5-dinitrosalicylic acid (DNS) and enzymatic-gravimetric methods, respectively (Garbelotti et al., 2003; Saqib \& Whitney, 2011). The total anthocyanin in PSP extract was determined by spectroscopy method (Amr \& Al-Tamimi, 2007), which the test wavelength was $530 \mathrm{~nm}$ and the content was expressed as cyanidin-3-glucoside equivalent.

\subsection{HPLC analysis of PSP anthocyanins}

PSP extract was purified before analysis, which was conducted on a column $(40 \times 3 \mathrm{~cm})$ of D101 macroporous adsorption resin using ethanol/water (50:50, v/v) as eluant. Samples were filtered through a $0.45 \mu \mathrm{m}$ millipore filter before HPLC injection. An Agilent 1100 liquid chromatograph system equipped with a reverse-phase C18 column $(150 \times 4.6 \mathrm{~mm}, 5 \mu \mathrm{m}$, GL-Science, Tokyo, Japan) was employed. The column temperature was $30{ }^{\circ} \mathrm{C}$, and the mobile phases included acetonitrile (M1) and $10 \%$ glacial acetic acid (M2). Elution was performed at a flow rate of $1 \mathrm{~mL} \mathrm{~min}^{-1}$ using a gradient of $10-25 \% \mathrm{M} 1$ for $0-15 \mathrm{~min}$ and $25-30 \% \mathrm{M} 1$ for $15-25 \mathrm{~min}$. The sample injection volume was $20 \mu \mathrm{L}$ and the detection was carried out at $530 \mathrm{~nm}$.

\subsection{Color stability test}

A few studies took CIE $L^{*}, a^{*}, b^{*}$ values as the index of color and investigated the color stability of some natural product extracts (Fan et al., 2008; Malien-Aubert et al., 2001). Spectrophotometric analysis was also adapted to similar research (Bakowska et al., 2003). Considering the fact that spectrophotometric method was widely applied in food factories, we used a UV-1800PC (Mapada, Shanghai) to study the color stability of PSP extract in this research. The absorbance at $\mathrm{pH}$ $2,4,6$ and 8 was measured over a range of wavelengths from 800 to $400 \mathrm{~nm}$. The changes in absorbance at $\lambda_{\max }(530 \mathrm{~nm})$, as affected by heat, light and the preheating treatments (steaming and baking) during extraction, were recorded during storage (15-30 d). Temperature tested included $4{ }^{\circ} \mathrm{C}$ and $20^{\circ} \mathrm{C}$. For light test, samples were either exposed to UV ( $8 \mathrm{~W}, 254 \mathrm{~nm})$ or white fluorescent light $(9 \mathrm{~W})$, or kept in dark.

\subsection{Statistical analysis}

All analyses were conducted in triplicate and data were presented as mean value \pm standard deviation (SD).

\section{Results and discussion}

\subsection{Compositions of PSP extract}

Three minerals, Se, Ca and $\mathrm{Mg}$, were found in the PSP extract by ICP analysis, which the contents were 4.02, 54.21, $60.83 \mathrm{ug} \mathrm{mL}^{-1}$, respectively. As a plant mineral source, this presence of Se, $\mathrm{Ca}$ and $\mathrm{Mg}$ in PSP extract is beneficial for human health. The anthocyanins content was $48.72 \mathrm{ug} \mathrm{mL}^{-1}$, suggesting a yield of $24.36 \mathrm{mg} / 100 \mathrm{~g}$ fresh PSP. Some other water-soluble compositions existed in the anthocyanin-based PSP extract which contained $17.11 \mathrm{mg} \mathrm{mL}^{-1}$ of protein, $0.44 \mathrm{mg} \mathrm{mL}^{-1}$ of dietary fiber and $2.82 \mathrm{mg} \mathrm{mL}^{-1}$ of reducing sugars. In a few studies, pure anthocyanins were used to explore the color stability (Fossen et al., 1998). But in this research, some water-soluble compositions coexist in PSP extract which may be nutritious besides serving as a natural colorant in food processing. A color stability study based on such extract is more referential in practice.

The typical absorbance of PSP extract was observed at $530 \mathrm{~nm}$ (Figure 1a), and the HPLC chromatogram displayed nine main peaks ( 1 to 9, Figure $1 \mathrm{~b}$ ) accounting for $3.14 \%, 4.43 \%$, 3.51\%, $3.91 \%, 8.81 \%, 16.15 \%, 18.48 \%, 31.46 \%$ and $5.40 \%$ of the total anthocyanins, respectively. As a group of phenolic compounds, hundreds of anthocyanins have been isolated from nature and cyanidin, peonidin, delphinidin and malvidin are the most prevalent ones found in fruits and vegetables. Fan et al. (2008) proved that the anthocyanins in purple sweet potato are mainly cyanidin and peonidin which are glycosylated with sugars. Tian et al. (2005) indicated that the glycosylated anthocyanins are commonly mono- or di-acylated with caffeic, ferulic and hydroxybenzoic acids. This structure complication leads to a big challenge to the identification of PSPAs. Although significant progress was made by using electrospray ionization mass spectrometry (ESI-MS) and tandem spectrometry (MS/MS) technologies, further studies are needed to characterize the structure of PSPAs.

Many anthocyanin-rich fruits and vegetables have been used to develop colorful product in food industry. But, due to the susceptibility of anthocyanins to processing and storage conditions, the product is very difficult to keep consistent in color during shelf life. This color instability becomes a bottleneck for the industrialization of anthocyanin-containing foods. Therefore, in order to promote the wide use of purple sweet potato in food processing, the color stability of obtained PSP extract was further investigated.

\subsection{Effect of pH on the color of PSP extract}

The various colors of anthocyanins in nature may be attributed to their different molecular structure, which is most susceptible to $\mathrm{pH}$ among all environmental factors. Even for an individual anthocyanin, the structure may vary with the $\mathrm{pH}$ of solution and 

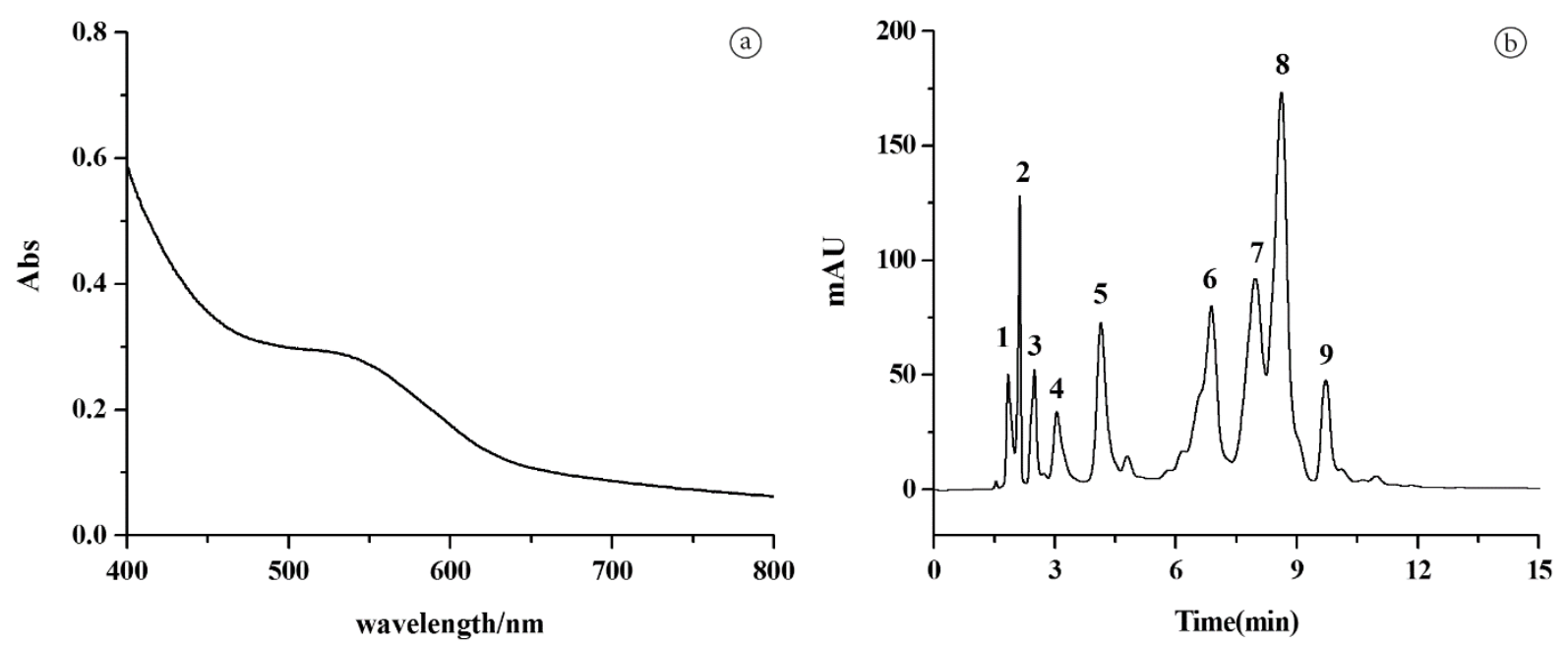

Figure 1. Visible spectra (a) and HPLC (b) of PSP extract (mobile phase: M1, acetonitrile, M2, 10\% glacial acetic acid; Column: GL-Science C18,

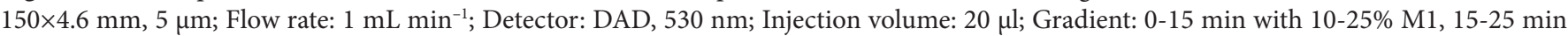
with $25-30 \% \mathrm{M} 1$ ).

result in different colors. The natural pH of PSP extract was 5.5, while it had typical absorbance $\left(\lambda_{\max }\right)$ at $530 \mathrm{~nm}$ and exhibited purple color. At pH 2.0, the anthocyanin-based extract was red and the $\lambda_{\max }$ was still observed at $530 \mathrm{~nm}$ (Figure 2), suggesting that the PAS anthocyanins predominantly existed in the form of flavylium cations (Cavalcanti et al., 2011). At pH 4 and pH 6, the spectra of PSP extract were nearly overlapped between $400 \mathrm{~nm}$ and $800 \mathrm{~nm}$ with $\lambda_{\max }$ at $530 \mathrm{~nm}$ (Figure 2). Castañeda-Ovando et al. (2009) reported that, at $\mathrm{pH}$ values between 4 and 6, an anthocyanin may occur as a mixture of four equilibrium forms including flavylium cation (red), quinonoidal base (purple), carbinol base (colorless) and chalcone (yellow). This structure coexistence of anthocyanins contributed to an integrated violet color when PSP extract was adjusted to $\mathrm{pH} 4$ and $\mathrm{pH} 6$. As the $\mathrm{pH}$ increased to 8 , the $\lambda_{\max }$ shifted to $610 \mathrm{~nm}$ (Figure 2) and the color of PSP extract converted to navy blue.

The $\mathrm{pH}$-dependent structures of anthocyanins may lead to different color stability during storage. Acylated cyanidin and peonidin predominate in PSPAs and these acylated structures are beneficial to the color stability of PSP extract in acid and neutral media (Malien-Aubert et al., 2001). As observed at pH $2, \mathrm{pH} 4$ and $\mathrm{pH} 6$, the $\lambda_{\max }$ and color intensity (absorbance at $\lambda_{\max }$ ) of PSP extract were almost stable in 15 days of storage at room temperature (data not shown). However, the sample at pH 8 exhibited certain instability which was visually confirmed by the difference in color during storage. This instability may result from a gradual process of anthocyanins degradation (Castañeda-Ovando et al., 2009) and phenolic hydroxyl oxidation (Lu et al., 2010), which are prone to take place in alkaline conditions. These results indicate that PSPAs are more stable at low $\mathrm{pH}$ values, and alkaline condition should be avoided when PSP extract is used as a colorant in food industry.

\subsection{Effect of temperature on the color of PSP extract}

The presence of hydroxyl groups in anthocyanins molecule may contribute to the color instability to heat. In addition, the ring-opening and degradation of anthocyanins were found to be the main factors responsible for the color change at high

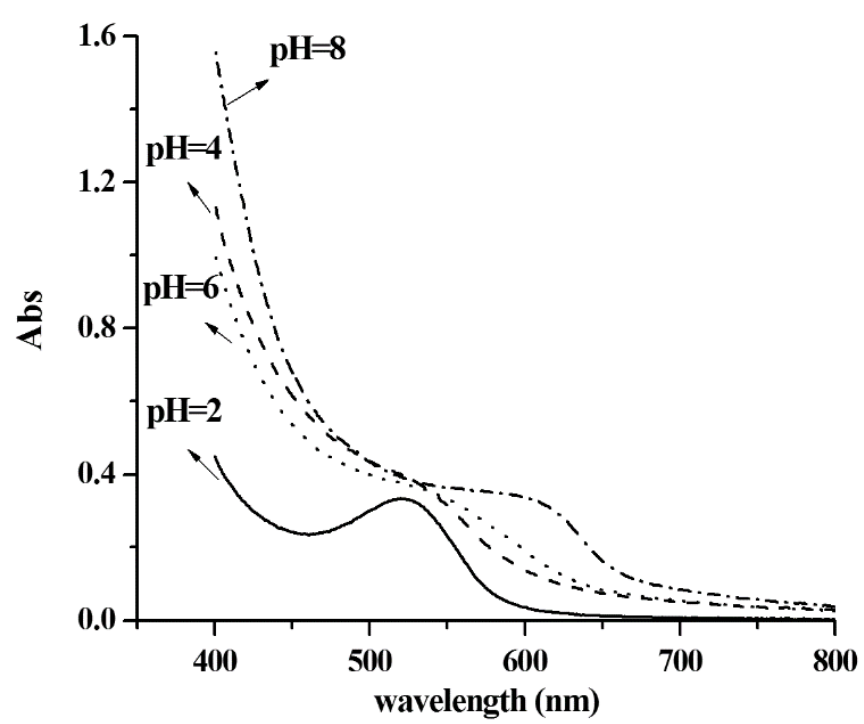

Figure 2. Visible spectra of PSP extract at $\mathrm{pH} 2,4,6$ and 8.

temperature. Many studies indicated that the color stability of anthocyanins decreases during storage as temperature rises. However, in this research, PSP extract displayed good thermal stability during 30 days of storage at $4{ }^{\circ} \mathrm{C}$ and $20^{\circ} \mathrm{C}$, which is in agreement with the results of Turker et al. (2004). As shown in Figure 3, at both temperatures, no substantial change in the absorbance at $530 \mathrm{~nm}$ was observed throughout the storage period. This result suggests that PSP extract may be stored at room temperature in food industry in consideration of storage cost.

The color stability observed at $4{ }^{\circ} \mathrm{C}$ and $20^{\circ} \mathrm{C}$ may be attributed to that PSP anthocyanins primarily exist in glycosylated and acylated forms which have significant stabilizing effect on anthocyanins structure. Many authors employed higher temperatures to explore the thermal stability of anthocyanins in food processing. Amr \& Al-Tamimi (2007) found that $42 \%$ and $48 \%$ of Ranunculus asiaticus anthocyanins were lost after 
$7 \mathrm{~h}$ of storage at $50{ }^{\circ} \mathrm{C}$ and $80^{\circ} \mathrm{C}$, respectively in $\mathrm{pH} 3.5$ buffer. Turker et al. (2004) reported that the decline of black carrots anthocyanins was accompanied by browning which increased rapidly after 24 days of storage at $40{ }^{\circ} \mathrm{C}$. Bakowska et al. (2003) indicated that temperature increase could cause the dissociation of anthocyanin-copigment complex, thus resulting in a loss of color. All the studies suggest that PSP extract may suffer anthocyanins loss and discoloration when it subjected to intensive heating.

\subsection{Effect of light on the color of PSP extract}

Light exposure was proved to be a significant factor determining the instability of anthocyanins (Cavalcanti et al., 2011), and it showed considerably negative effect on the color stability of PSP extract. As shown in Figure 4, PSP extract had stable color in dark, which the absorbance at $530 \mathrm{~nm}$ kept almost

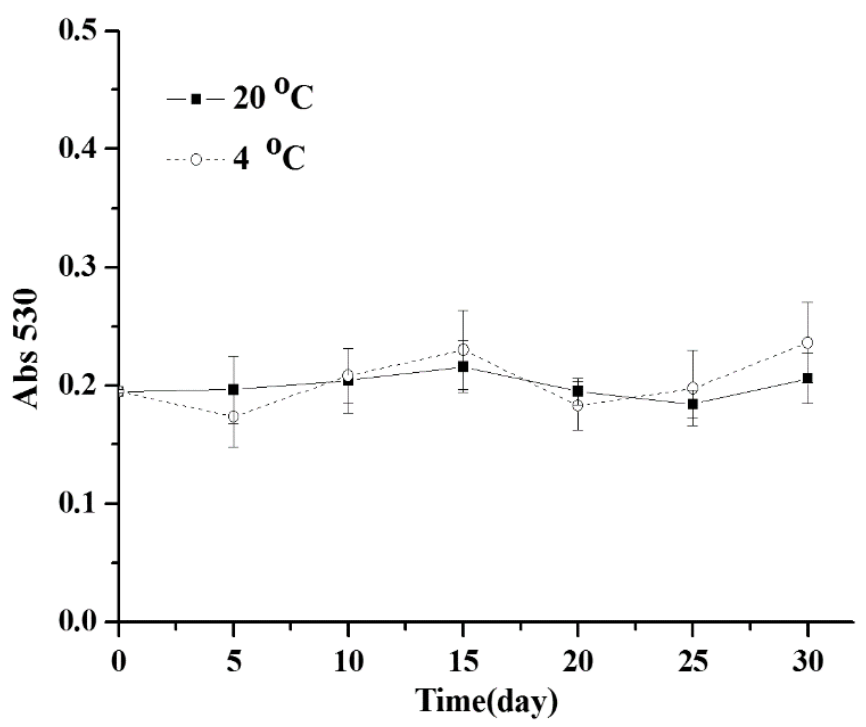

Figure 3. Color stability of PSP extract at $4{ }^{\circ} \mathrm{C}$ and $20^{\circ} \mathrm{C}$ (pH 5.5, in dark).

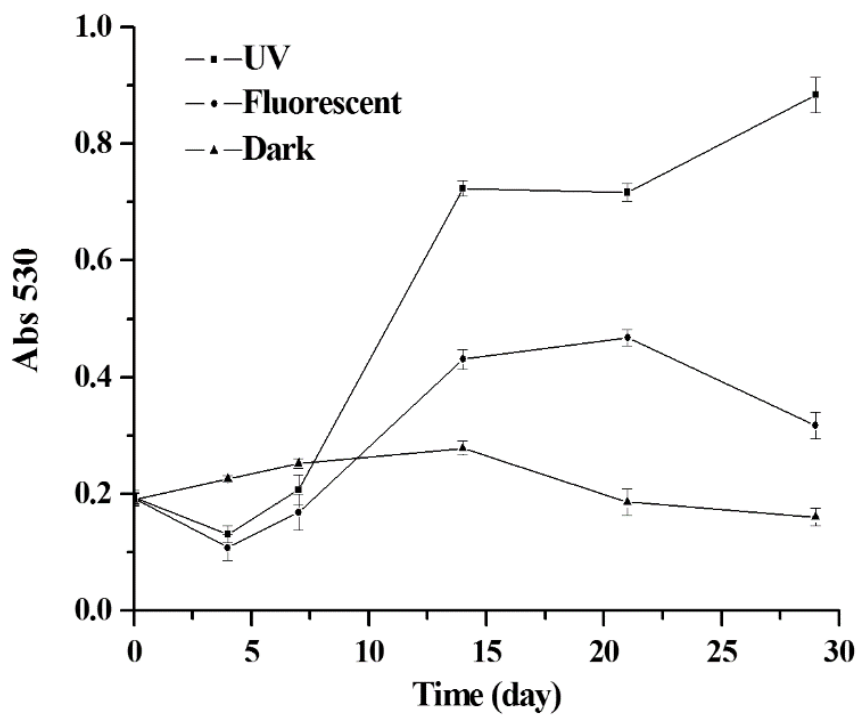

Figure 4. Color stability of PSP extract exposed to UV (8 W, $254 \mathrm{~nm})$ and fluorescent light (9 W), and kept in dark ( $\mathrm{pH} 5.5$, room temperature). unchanged during 30 days of storage at room temperature. However, the samples exhibited varying color when stored under UV and fluorescent light irradiation. Both PSP extracts exposed to UV and fluorescent light displayed a decrease in absorbance during the first 4 days, which occurred due to the degradation of PSP anthocyanins. This observation is similar to the photo-degradation of anthocyanins extracted from Tibouchina semidecandra flowers (Janna et al., 2007). Another reason for the decrease in absorbance may be that light exposure weakens the stability of some anthocyanin-copigment complexes in PSP extract (Bakowska et al., 2003). Owing to the degradation of anthocyanins and anthocyanin-copigment complexes, as well as the oxidation of phenolic hydroxyls, many byproducts may accumulate in solution during the first 4 days. Afterwards, as a result of polymerization reactions between the byproducts themselves and between them and some other compositions in PSP extract, both UV and fluorescent exposure led to remarkable increase in absorbance. UV showed a more drastic effect in comparison, which may be attributed to its potential to induce the oxidation of phenolic hydroxyls in PSP anthocyanins (Benitez et al., 2001). At the end of storage, a little decrease in absorbance was observed in the case of fluorescent irradiation, which may result from the instability of some polymeric intermediates formed. These observations indicate that light exposure can intensively weaken anthocyanins stability and a suitable condition for the storage of PSP extract is in dark at room temperature.

\subsection{Effect of preheating treatments on the color of PSP extract}

Enzyme is an important factor for the instability of anthocyanins, because it can catalyze the degradation and browning of anthocyanins during extraction and storage. Therefore, inactivation of enzymes is crucial for PSP processing to keep a natural and consistent product color during shelf life. In this research, fresh PSP pieces were steamed or baked before extraction step, and effects of the two preheating treatments on the color of PSP extract were investigated.

As shown in Figure 5, the PSP extracts in both cases remained relatively stable absorbance at $530 \mathrm{~nm}$ during storage, suggesting that both steaming and baking treatments are beneficial for stabilizing the color of PSP extract. Glycosidase and polyphenol oxidase naturally occur in fruits and vegetables, which are the two most common enzymes responsible for the instability of anthocyanins. Glycosidase can break the glycoside bonds in anthocyanins molecule, while polyphenol oxidase accelerates the oxidation of phenolic hydroxyls. Both steaming and baking treatments can inactivate glycosidase and polyphenol oxidase, so that no remarkable change in the absorbance of PSP extract was observed during storage. Comparatively, the PSP extract from steaming process kept the natural color, while baking treatment allowed the extract a higher absorbance at $530 \mathrm{~nm}$. This is most likely due to non-enzymatic browning (Maillard reaction) which easily takes place between protein and reducing sugar in a dry heat condition (Cernîşev, 2010). Results above suggest that, in food processing, steaming treatment can benefit the color of PSP product by inactivating enzymes and preventing possible non-enzymatic browning. 


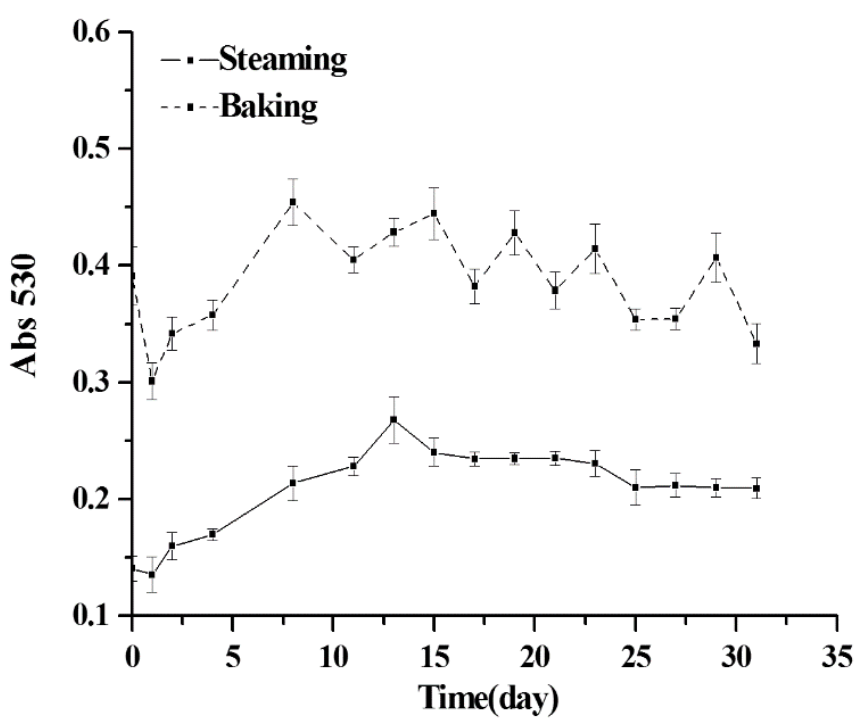

Figure 5. Color stability of PSP extract affected by steaming and baking pretreatments ( $\mathrm{pH} 5.5$, in dark, room temperature).

\section{Conclusion}

Nine individual anthocyanins and some other compositions including minerals, protein, dietary fiber and reducing sugars coexisted in the aqueous extract of purple sweet potato (PSP). In order to keep a stable color, the suitable storage conditions for the PSP extract are at room temperature and $\mathrm{pH}$ 2.0-6.0 in dark. A steaming pretreatment of fresh PSP is beneficial to the color stability of PSP extract. Results suggest that the anthocyanin-based PSP extract is nutritious besides serving as a natural colorant, which is a positive implication for the wide use of purple sweet potato in food industry.

\section{Acknowledgements}

This project is financially supported by National Natural Science Foundation of China (31171656) and the National Science \& Technology Pillar Program (2012BAD37B09).

\section{References}

Amr, A., \& Al-Tamimi, E. (2007). Stability of the crude extracts of Ranunculus asiaticus anthocyanins and their use as food colourants. International Journal of Food Science \& Technology, 42(8), 985-991. http://dx.doi.org/10.1111/j.1365-2621.2006.01334.x.

Bakowska, A., Kucharska, A. Z., \& Oszmiański, J. (2003). The effects of heating, UV irradiation, and storage on stability of the anthocyaninpolyphenol copigment complex. Food Chemistry, 81(3), 349-355. http://dx.doi.org/10.1016/S0308-8146(02)00429-6.

Benitez, F. J., Beltran-Heredia, J., Acero, J. L., \& Rubio, F. J. (2001). Oxidation of several chlorophenolic derivatives by UV irradiation and hydroxyl radicals. Journal of Chemical Technology and Biotechnology, 76(3), 312-320. http://dx.doi.org/10.1002/jctb.384.

Castañeda-Ovando, A., Pacheco-Hernández, M. L., Páez-Hernández, M. E., Rodríguez, J. A., \& Galán-Vidal, C. A. (2009). Chemical studies of anthocyanins: a review. Food Chemistry, 113(4), 859-871. http:// dx.doi.org/10.1016/j.foodchem.2008.09.001.
Cavalcanti, R. N., Santos, D. T., \& Meireles, M. A. A. (2011). Nonthermal stabilization mechanisms of anthocyanins in model and food systems - an overview. Food Research International, 44(2), 499-509. http://dx.doi.org/10.1016/j.foodres.2010.12.007.

Cernîşev, S. (2010). Effects of conventional and multistage drying processing on non-enzymatic browning in tomato. Journal of Food Engineering, 96(1), 114-118. http://dx.doi.org/10.1016/j. jfoodeng.2009.07.002.

Cho, J., Kang, J. S., Long, P. H., Jing, J., Back, Y., \& Chung, K. S. (2003). Antioxidant and memory enhancing effects of purple sweet potato anthocyanin and cordyceps mushroom extract. Archives of Pharmacal Research, 26(10), 821-825. http://dx.doi.org/10.1007/BF02980027. PMid:14609130.

Fan, G., Han, Y., Gu, Z., \& Gu, F. (2008). Composition and colour stability of anthocyanins extracted from fermented purple sweet potato culture. LWT - Food Science and Technology, 41(8), 14121416. http://dx.doi.org/10.1016/j.lwt.2007.09.003.

Fossen, T., Cabrita, L., \& Andersen, O. M. (1998). Colour and stability of pure anthocyanins influenced by $\mathrm{pH}$ including the alkaline region. Food Chemistry, 63(4), 435-440. http://dx.doi.org/10.1016/ S0308-8146(98)00065-X.

Garbelotti, M. L., Marsiglia, D. A. P., \& Torres, E. A. F. S. (2003). Determination and validation of dietary fiber in food by the enzymatic gravimetric method. Food Chemistry, 83(3), 469-473. http://dx.doi. org/10.1016/S0308-8146(03)00226-7.

Hwang, Y. P., Choi, J. H., Choi, J. M., Chung, Y. C., \& Jeong, H. G. (2011). Protective mechanisms of anthocyanins from purple sweet potato against tert-butyl hydroperoxide-induced hepatotoxicity. Food and Chemical Toxicology, 49(9), 2081-2089. http://dx.doi.org/10.1016/j. fct.2011.05.021. PMid:21640154.

Janna, O., Khairul, A., \& Maziah, M. (2007). Anthocyanin stability studies in Tibouchina semidecandra L. Food Chemistry, 101(4), 1640-1646. http://dx.doi.org/10.1016/j.foodchem.2006.04.034.

Kamizake, N. K. K., Gonçalves, M. M., Zaia, C. T. B. V., \& Zaia, D. A. M. (2003). Determination of total proteins in cow milk powder samples: a comparative study between the Kjeldahl method and spectrophotometric methods. Journal of Food Composition and Analysis, 16(03), 507-516. http://dx.doi.org/10.1016/S0889-1575(03)00004-8.

Lien, C., Chan, C., Lai, Y., Huang, C., \& Liao, W. C. (2012). Ultrasoundassisted anthocyanin extraction of purple sweet potato variety TNG73, Ipomoea batatas, L. Separation Science and Technology, 47(8), 1241-1247. http://dx.doi.org/10.1080/01496395.2011.644610.

Lu, L., Zhou, Y., Zhang, Y., Ma, Y., Zhou, L., Li, L., Zhou, Z., \& He, T. (2010). Anthocyanin extracts from purple sweet potato by means of microwave baking and acidified electrolysed water and their antioxidation in vitro. International Journal of Food Science \& Technology, 45(7), 1378-1385. http://dx.doi.org/10.1111/j.13652621.2010.02271.x.

Malien-Aubert, C., Dangles, O., \& Amiot, M. J. (2001). Color stability of commercial anthocyanin-based extracts in relation to the phenolic composition. Protective effects by intra- and intermolecular copigmentation. Journal of Agricultural and Food Chemistry, 49(1), 170-176. http://dx.doi.org/10.1021/jf000791o. PMid:11170573.

Montilla, E. C., Hillebrand, S., Butschbach, D., Baldermann, S., Watanabe, N., \& Winterhalter, P. (2010). Preparative isolation of anthocyanins from Japanese purple sweet potato (Ipomoea batatas L.) varieties by high-speed countercurrent chromatography. Journal of Agricultural and Food Chemistry, 58(18), 9899-9904. http://dx.doi.org/10.1021/ jf101898j. PMid:20731350. 
Saqib, A. A. N., \& Whitney, P. J. (2011). Differential behaviour of the dinitrosalicylic acid (DNS) reagent towards mono- and di-saccharide sugars. Biomass and Bioenergy, 35(11), 4748-4750. http://dx.doi. org/10.1016/j.biombioe.2011.09.013.

Tian, Q., Konczak, I., \& Schwartz, S. J. (2005). Probing anthocyanin profiles in purple sweet potato cell line (Ipomoea batatas L. Cv. Ayamurasaki) by high-performance liquid chromatography and electrospray ionization tandem mass spectrometry. Journal of Agricultural and Food Chemistry, 53(16), 6503-6509. http://dx.doi. org/10.1021/jf050671m. PMid:16076141.
Turker, N., Aksay, S., \& Ekiz, H. I. (2004). Effect of storage temperature on the stability of anthocyanins of a fermented black carrot (Daucus carota var. L.) beverage: shalgam. Journal of Agricultural and Food Chemistry, 52(12), 3807-3813. http://dx.doi.org/10.1021/jf049863s. PMid:15186101.

Zhang, Z. F., Fan, S. H., Zheng, Y. L., Lu, J., Wu, D. M., Shan, Q., \& Hu, B. (2009). Purple sweet potato color attenuates oxidative stress and inflammatory response induced by d-galactose in mouse liver. Food and Chemical Toxicology, 47(2), 496-501. http://dx.doi.org/10.1016/j. fct.2008.12.005. PMid:19114082. 